\title{
FLUXO DE TECNOLÓGICA INTERSETORIAL E PRODUTIVIDADE NO BRASIL: 2000-2014
}

\section{Resumo}

Felipe Queiroz Silva ${ }^{1}$ Carlos Frederico Leão Rocha ${ }^{2}$

O objetivo deste artigo é analisar o impacto dos fluxos tecnológicos intersetoriais sobre a produtividade no Brasil durante o período de 2000 a 2014. A análise é feita em nível setorial e utiliza a abordagem metodológica de insumo-produto para a construção de matrizes de fluxos tecnológicos entre os setores da economia. Essas matrizes incorporam dados de gastos em $\mathrm{P} \& \mathrm{D}$ como estimativas de esforços inovativos incorporados na aquisição de bens de consumo intermediário e bens de capital dos setores econômicos. Especificamente, objetiva-se responder a seguinte questão de pesquisa: Qual é o impacto do fluxo intersetorial de tecnologia sobre a produtividade setorial no Brasil? Por meio de estimações econométricas de painel dinâmico, verificouse que os esforços inovativos incorporados nos bens transacionados pelos setores econômicos são até mais importantes para explicar o crescimento da produtividade do trabalho do que os esforços inovativos dos próprios setores. Isso mostra que boa parte do crescimento da produtividade de alguns setores no Brasil se deu por inovações geradas em outros setores e que os fluxos tecnológicos e a interdependência setorial são um importante mecanismo de crescimento da produtividade.

Palavras-chave: Inovação, Produtividade, Fluxos Tecnológicos, Matriz de insumo-produto

\begin{abstract}
The aim of this paper is to analyze the impact of intersectoral technological flows on productivity in Brazil during the period from 2000 to 2014 . The analysis is done at the sectoral level and uses the methodological approach of input-output for the construction of technological flows matrices between the sectors of the economy. These matrices incorporate $R \& D$ data as estimates of innovative efforts incorporated in the acquisition of intermediate consumer goods and capital goods from the economic sectors. Specifically, we aim to answer the following research question: What is the impact of the intersectoral flow of technology on productivity in Brazil? Through dynamic panel estimators, it has been found that the innovative efforts incorporated in goods transacted by the economic sectors are more important to explain labor productivity growth than the innovative efforts of the sectors themselves. This shows that much of the productivity growth of some sectors in Brazil was due to innovations generated in other sectors and that technological flows are an important mechanism of productivity growth.
\end{abstract}

Keywords: Innovation; Productivity; Intersectorial Technology Flow; Input-output matrix

Área 1.3: Crescimento, Produtividade e Competitividade JEL: C67; L16; O33; O47

\footnotetext{
${ }^{1}$ Doutor em Economia da Indústria e Tecnologia do Instituto de Economia da UFRJ.

${ }^{2}$ Professor do Instituto de Economia da UFRJ.
} 


\section{Introdução}

O debate econômico sobre os determinantes do crescimento econômico de longo prazo e da produtividade é antigo e ainda longe de se esgotar. Entre os vários estudos e fatores que tiveram essa finalidade, destaca-se, sobretudo, a questão da mudança tecnológica ou da inovação. Utilizando a definição usual de uma função de produção, na qual o resultado (output) depende dos fatores de produção empregados (inputs), verifica-se que, quanto maior for a relação entre a quantidade produzida e os fatores utilizados, maior será a produtividade. Espera-se, assim, que quanto mais eficientemente uma economia conseguir empregar os seus fatores, mais produtiva será. A mudança tecnológica, com o incremento de novas técnicas e novos produtos, seria um dos fatores essenciais para que esse processo ocorresse.

O procedimento básico descrito no parágrafo anterior é verdadeiro em qualquer nível de agregação em que se queira estudar, porém, torna-se cada vez mais complexo à medida em que esta agregação se torna menor. A relação entre inovação e produtividade está sujeita a um sistema técnico-econômico complexo de fluxos entre agentes econômicos que não são percebidos em nível macroeconômico. O fluxo de tecnologia entre empresas ou setores de uma economia é uma característica importante na percepção da mudança tecnológica e do crescimento econômico. A maioria das inovações produzidas e incorporadas em novos produtos por um setor são utilizadas como melhorias no processo produtivo de outros setores, que resultam em ganhos de produtividade (e.g. SCHMOOKLER, 1966; SCHERER, 1982), bem como as relações de compra e venda entre setores produtores e usuários de inovação são determinantes para o próprio desenvolvimento da tecnologia (e.g. LUNDVAL, 1988).

A interdependência setorial e suas implicações são objeto de estudo da tradição empírica de insumoproduto. Porém, a mesma oferece apenas uma abordagem estática de trocas do sistema produtivo de uma economia. Visto que a mudança tecnológica é o principal fator relacionado ao aumento da produtividade e do crescimento econômico de longo prazo, incorporar a tecnologia ou o conhecimento nas matrizes de insumoproduto setoriais é essencial para evidenciar o funcionamento de um sistema econômico complexo. Dessa forma, a interdependência tecnológica setorial passa a ser um instrumento de análise empírica mais poderoso do que a simples interpendência (produtiva) setorial, pois as relações que envolvem trocas de tecnologia ou conhecimento são susceptíveis de serem mais complexas do que setores que possuem ligações "comuns" de uma abordagem tradicional. Os fluxos intersetoriais de tecnologia forneceriam a estrutura de um sistema tecnológico ou de uma parte importante do sistema nacional de inovação de uma economia, revelando suas particularidades e esclarecendo como esses podem se relacionar com os ganhos de produtividade.

Observa-se que grande parte dos estudos internacionais recentes sobre inovação e produtividade não levam em consideração os aspectos de fluxos de tecnologia entre os agentes econômicos. Com a popularização e a disponibilidades de microdados de surveys de inovação, cresceu bastante o número de estudos empíricos econométricos em nível da firma. Algumas dessas evidências empíricas recentes foram compiladas e revisadas de forma analítica por Mohnen e Hall (2013). Entre os principais resultados encontrados pelos autores estão as evidências de que há um impacto positivo da inovação de produto sobre a produtividade e de que a relação desta última com a inovação de processo é ambígua e geralmente negativa. Esse último resultado não era esperado, já que o aumento da produtividade deveria surgir justamente do corte de custos através de técnicas de produção mais eficientes.

Uma maneira de buscar converter os problemas das especificações dos modelos analisados por Mohnen e Hall (2013) é observar o impacto da inovação de produto de uma empresa sobre a produtividade de outra empresa usuária dessa inovação. Dessa maneira, inovações de produto ganham destaque, já que produtos novos ou melhorados de uma empresa muitas vezes são incorporados como novos processos produtivos para outras empresas. Assim, grande parte das inovações de processo são representadas pelas inovações de produto externos à empresa usuária. Dada esta hipótese, os ganhos de produtividade estariam relacionados mais com os usuários de inovações do que com os produtores, e isso poderia ser analisado por meio dos fluxos tecnológicos. 
Fazer a análise estatística descrita no parágrafo anterior em nível da empresa é muito difícil devido à falta de dados em quantidade suficiente que relacione as relações de empresas específicas. Porém, com o uso de tabelas de matrizes de insumo-produto disponíveis, essa análise pode ser feita em nível setorial de todo o sistema produtivo de uma economia. Esse tipo de estudo que busca as relações tecnológicas intersetoriais com base nas matrizes de insumo-produto já foi utilizado pela literatura nos países desenvolvidos desde Terleckyj (1980) e Scherer (1982), porém, vem sendo pouco aproveitada nos últimos anos devido a popularização de base de dados em nível da firma, que não conseguem captar este efeito entre empresas ou entre setores.

A partir dos problemas destacados, formula-se a seguinte pergunta de pesquisa: Qual é o impacto do fluxo intersetorial de tecnologia ou conhecimento sobre a produtividade setorial no Brasil? A hipótese é de que a tecnologia ou o conhecimento incorporado nos produtos de alguns setores industriais são destinados a outros setores da economia, que os utilizam como melhorias em seu processo produtivo, acumulando conhecimento e resultando, por sua vez, em ganhos de produtividade. Dessa maneira, boa parte dos ganhos de produtividade em decorrência de novos produtos produzidos por um setor passa para os setores usuários destes. De maneira geral, a produtividade também deve ser influenciada pela tecnologia incorporada nos produtos dos setores que estão atrás da cadeia produtiva (fornecedores) do que apenas pela tecnologia gerada pelo próprio setor em questão. Assim, o objetivo principal deste artigo é analisar o impacto dos fluxos tecnológicos intersetoriais sobre a produtividade no Brasil durante o período de 2000 a 2014. A análise é feita em nível setorial e utiliza a abordagem metodológica de insumo-produto para a construção de matrizes de fluxos tecnológicos entre os setores da economia. Essas matrizes utilizam dados de gastos em P\&D como estimativas de esforços inovativos incorporados na aquisição de bens de consumo intermediário e bens de capital dos setores econômicos.

Estudos da relação entre fluxos tecnológicos e produtividade por meio de matrizes de insumo-produto foram muito pouco utilizados na literatura econômica, não tendo sido encontrada nenhuma aplicação para a América Latina. Assim, o estudo também visa contribuir para o debate de economia industrial e da tecnologia com uma aplicação ainda não testada para o Brasil. Análises de fluxos tecnológicos também podem trazer contribuições e evidências importantes para formuladores de políticas públicas, já que relações intersetoriais do ponto de vista da tecnologia ou do conhecimento e de seus efeitos ao longo de suas cadeias produtivas são instrumentos de interesse para a formulação de estratégias e políticas de desenvolvimento econômico.

Além dessa introdução, o artigo está estruturado em mais quatro seções. A seção 2 apresenta uma revisão bibliográfica de abordagens e estudos empíricos sobre inovação, fluxos tecnológicos e produtividade. A seção 3 apresenta o modelo insumo-produto e a construção das matrizes de fluxos tecnológicos, bem como detalhes da base de dados e da construção de modelos econométricos a serem estimados. Por fim, a seção 4 apresenta os resultados da pesquisa, enquanto a seção 5 apresenta as considerações finais.

\section{Inovação, fluxos tecnológicos e produtividade}

Numa abordagem de economia industrial em nível setorial e em nível da empresa, a análise empírica da relação causal entre inovação e produtividade teve como principal precursor os trabalhos de Zvi Griliches, centrados numa abordagem econométrica de estimação da função de produção nos mesmos moldes da perspectiva macroeconômica de Solow. Em um artigo seminal, Griliches (1979) delimitou as bases metodológicas para a sua abordagem, que influenciou a maioria dos estudos posteriores. $\mathrm{O}$ autor criou o conceito de estoque de conhecimento da firma, que assim como os fatores de capital e trabalho, entraria como um input de produção. Esse fator de estoque de conhecimento tinha como variável proxy principal o investimento em pesquisa e desenvolvimento (P\&D).

Mais recentemente, com a maior disponibilidade de microdados a partir de surveys de inovação por parte de institutos de pesquisa com base no Manual de Oslo (OCDE, 2005), cresceu bastante o número de estudos que aplicam os conceitos de Griliches (1979) de forma mais aprofundada. Um modelo bastante citado e replicado em outros trabalhos é o do Crépon, Duguet e Mairesse (1998). As implicações dos autores ficaram conhecidas na literatura como Modelo CDM e possuem a principal característica de inserir a hipótese de que a inovação propriamente dita é um processo intermediário entre a decisão e a intensidade de se investir em 
P\&D e o resultado da produtividade. Outra característica marcante do modelo é a estrutura de estimações em etapas, bem como técnicas mais robustas com a finalidade de evitar o problema de endogeneidade entre as variáveis de $\mathrm{P} \& \mathrm{D}$, inovação e produtividade.

Algumas evidências empíricas recentes dos estudos sobre inovação e produtividade em nível da firma em vários países, que em sua maioria utilizaram o modelo CDM, foram compiladas e revisadas de forma analítica por Mohnen e Hall (2013). Entre as principais conclusões dos autores estão: i) há uma substancial evidência de um impacto positivo do nível de gasto em P\&D de uma firma sobre a introdução de inovações, seja ela de produto ou processo; ii) no entanto, o impacto da introdução de inovações de produto e processo sobre a produtividade é ambígua e apresenta comportamentos distintos nos vários trabalhos que replicaram o modelo. Na maioria dos trabalhos, não há uma relação estatisticamente significativa da introdução de uma inovação de processo por uma firma sobre a sua produtividade, e, em alguns casos, essa relação chega a ser negativa ${ }^{3}$. Já em outros trabalhos ocorre o oposto, no qual a relação entre inovação de produto e produtividade não apresenta relação causal. Estes resultados são surpreendentes, principalmente no que se refere à inovação de processo. Teoricamente, o aumento da produtividade surge justamente do corte de custos através de técnicas de produção mais eficientes, que numa abordagem neoclássica, por exemplo, deslocarão a função de produção para um nível em que se produza mais com a mesma quantidade de fatores.

Uma hipótese razoável sobre os motivos de não haver um impacto entre inovação de processo e produtividade nesses estudos é de que há problemas de mensuração da inovação nos surveys com base no Manual de Oslo (OCDE, 2005), que não conseguem captar o real efeito da inovação de processo quando colocada junto a inovação de produto, ou simplesmente pela dificuldade de mensuração e coleta desse tipo de dado ${ }^{4}$. Outra hipótese levantada por Mohnen e Hall (2013) é que, como a produtividade geralmente é medida pelo valor da receita ou do valor adicionado sobre o número de trabalhadores, a inovação de produto cria um poder de mercado que aumenta a receita. Por outro lado, as melhorias de eficiência das inovações de processo podem não aparecer no valor da receita se essas melhorias resultarem em preços mais baixos sem um aumento correspondente na produção (ao menos no curto prazo).

Esse problema de mensuração da inovação de processo sobre a produtividade já havia sido percebido por Scherer (1984) em um contexto de fluxo de tecnologia intersetorial. O autor chamava a atenção que a maior parte dos esforços inovativos de uma empresa são orientados para a criação e melhorias de novos produtos a serem vendido para outras empresas, o que distingue dos esforços de melhorias de processo de produção usados internamente. Os estudos empíricos entre inovação e produtividade focavam e continuam em sua maioria se especializando no impacto da introdução de uma inovação por uma empresa $i$ sobre a produtividade desta mesma empresa $i$, enquanto o importante a ser testado é o impacto da inovação desta firma $i$ para o desempenho da produtividade de uma firma $j$ (SCHERER, 1984).

Dessa maneira, para determinar os reais efeitos da produtividade dos novos produtos, deve-se traçar o fluxo de tecnologia de uma indústria em que um novo produto foi originado para as indústrias que utilizam esse produto. Esse pode ser um dos motivos de por que as inovações de processo nos trabalhos empíricos econométricos recentes não estão relacionadas com maior produtividade, já que essa relação exige um entendimento em nível interfirma ou intersetorial. O efeito mais importante passa a ser, portanto, na relação entre indústrias produtoras de novos produtos e indústrias usuárias dessas inovações, no qual a inovação é essencialmente de produto, mas utilizada como um novo processo produtivo por outras indústrias. Uma limitação dessa abordagem é de que a mesma apenas é possível em nível setorial por causa da existência de matrizes de insumo-produto, o que é difícil conseguir em nível da firma.

Um dos primeiros autores a observar a importância dos fluxos tecnológicos foi Gustafson (1962) ao questionar alguns trabalhos empíricos de sua época sobre a má especificação dos modelos que tentavam

\footnotetext{
${ }^{3}$ Os autores analisaram mais de 30 trabalhos sobre os efeitos da inovação sobre a produtividade com dados em nível da firma em vários países diferentes.

${ }^{4}$ Os surveys de inovação com base no manual de Oslo utilizam de perguntas binárias sobre a introdução de inovação de produto e/ou processo, o que impede uma classificação qualitativa do mesmo. A definição do que seria inovação, em qualquer aspecto, também é problemática e pode incorrer em erro de interpretação pelas empresas respondentes.
} 
relacionar inovação e produtividade em nível setorial. Para o autor, o gasto em P\&D por uma firma era em sua maioria voltada para a criação de novos produtos, que só apresentariam melhorias de produtividade (redução de custos) para firmas usuárias desses novos produtos. Schmookler (1966) propôs uma solução a esse problema a partir de uma extensão da análise de insumo-produto de Leontief com a incorporação de um fluxo de "invenção". Nesse caso, as linhas da matriz representariam as indústrias que produziriam as invenções, as colunas seriam ocupadas pelos setores que usariam essas invenções, e os elementos da diagonal principal representariam as invenções de processo.

Terleckyj (1980) e Scherer (1982) foram os primeiros autores que testaram a abordagem construída por Schmookler (1966) ao atribuírem valores de P\&D e/ou patentes nas matrizes de insumo-produto dos Estados Unidos. Utilizando uma imputação dos valores de P\&D industriais nos coeficientes técnicos da matriz de insumo-produto, Terleckyj (1980) chegou à conclusão de que o retorno do gasto em P\&D de um mesmo setor sobre a sua produtividade foi em torno de $29 \%$, enquanto o retorno do P\&D incorporado através da compra de produtos e insumos de outros setores foi, em média, de $78 \%$, o que evidencia o maior poder explicativo da tecnologia incorporada.

Já Scherer (1982) utilizou um modelo mais complexo e trabalhoso ao também incorporar dados de patentes. $\mathrm{O}$ autor, junto com uma equipe de engenheiros e especialistas, analisou mais de 15 mil patentes e classificou-as entre os setores produtores e usuários de cada uma dessas patentes na matriz de insumo-produto. Ao montar uma matriz de patentes, os gastos em P\&D setoriais foram incorporados nos fluxos estabelecidos. Scherer (1982) verificou que 75\% das inovações introduzidas nos EUA entre 1964 e 1978 eram de produtos especialmente voltados para outras firmas, e que, assim como em Terleckyj (1980), a produtividade dos setores possuía uma relação com o P\&D incorporado através da aquisição de produtos de outros setores maior do que o P\&D produzido internamente.

A abordagem trabalhosa de Scherer (1982) foi replicada com os mesmos dados pelo próprio autor anos mais tarde em Scherer (2003), agora utilizando um fluxo de tecnologia intersetorial de maneira mais simples com a incorporação do P\&D setorial sem considerar o trabalho exaustivo de uma matriz de patentes. Os resultados foram muito parecidos entre as duas abordagens, evidenciando que o fluxo de tecnologia intersetorial pode ser utilizado com o uso de técnicas menos dispendiosas.

Paralelamente ao trabalho de Scherer (1982), Momigliano e Siniscalco (1982, 1984) sugeriram um processo mais sofisticado e rigoroso na construção da matriz de fluxos tecnológicos. Os autores se basearam no conceito de setores verticalmente integrado de Pasinetti (1973). Esse tipo de abordagem explicita tanto os fluxos diretos quanto os indiretos ao também levarem em consideração os componentes da demanda final da matriz de insumo-produto, e forneceram uma figura mais completa de toda a interrelacionalidade tecnológica do sistema de produção. Os autores aplicaram seus conceitos para a economia italiana e perceberam que um pouco mais de $50 \%$ do gasto em P\&D era incorporado em novos produtos.

A partir dos trabalhos de Scherer (1982) e Momigliano e Siniscalco (1982, 1984), vários outros autores replicaram os conceitos de fluxo de tecnologia intersetorial com pequenas variações de seus modelos. Entre estes trabalhos, encontram-se os de Griliches e Lichtenberg (1984), Verspagen (1997a) e Wolff (1997; 2012), que também utilizaram dados dos EUA, Verspagen (1997b), com dados de países europeus, Sterlacchini (1989) e Geroski (1991) com dados do Reino Unido, Goto e Suzuki (1989) com dados do Japão, Hanel (1994) com dados do Canadá e Van Meijl (1997) com dados da França. Todos estes trabalhos encontraram as mesmas conclusões destacados nos parágrafos anteriores: o P\&D incorporado na compra de novos produtos é mais importante para explicar o crescimento da produtividade dos setores industriais do que o P\&D próprio desses mesmos setores.

Alguns trabalhos listados no parágrafo anterior também evidenciaram algumas considerações importantes. Geroski (1991), por exemplo, aplicou alguns testes sobre a defasagem temporal dos efeitos do gasto em P\&D intersetorial sobre a produtividade. Nos testes realizados pelo autor, os esforços inovativos realizados em anos anteriores parece impactar mais a produtividade do que os esforços realizados em anos mais recentes. Já Goto e Suzuki (1989) fez alguns testes sobre setores relacionados a tecnologias eletrônicas. Partindo do princípio de que vários setores distintos utilizam tecnologias de base eletrônica (por exemplo: 
computadores), os autores encontraram que a difusão tecnológica incorporada nesses produtos afeta mais outras indústrias relacionadas ao mesmo tipo de tecnologia (por exemplo: máquinas e equipamentos eletrônicos) do que o restante das outras indústrias. Essas considerações ajudam a esclarecer algumas características do processo inovativo, sendo relevante compreender a defasagem temporal dos efeitos da inovação e da proximidade tecnológica dos setores industriais.

\section{Metodologia}

A metodologia do artigo consiste, primeiro, na construção de matrizes de fluxos tecnológicos por meio dos dados de matrizes de insumo-produto e de variáveis de gastos em P\&D em nível setorial. Construído essas matrizes, estima-se os fluxos tecnológicos intersetoriais sobre a produtividade dos setores da economia brasileira entre 2000 e 2014. As próximas subseções apresentam a construção desse arcabouço, bem como os detalhes acerca da base de dados utilizada.

\subsection{Matrizes de fluxos tecnológicos}

Dado o sistema econômico representado pela notação da matriz de insumo-produto, a relação entre o valor da produção e a demanda final (consumo final, exportações e investimentos) pode ser determinado pela equação 1:

$$
x=A x+y
$$

Onde: $x$ é o vetor do valor bruto da produção; $A$ é a matriz dos coeficientes técnicos diretos de produção; e $y$ é o vetor de demanda final.

Os elementos da matriz $A$ são dados por:

$$
a_{i j}=\frac{z_{i j}}{x_{j}}
$$

Onde: $a_{i j}$ é coeficiente técnico direto que indica a quantidade de insumo do setor $i$ necessária para a produção de uma unidade de produto final do setor $j ; z_{i j}$ é o consumo intermediário que indica o valor gasto pelo setor $j$ com a compra de insumos produzidos pelo setor $i$; e $x_{j}$ é o valor bruto da produção do setor $j$. Expresso em unidades monetárias, a matriz de coeficientes técnicos diretos indica quantos Reais $(\mathrm{R} \$) \mathrm{em}$ insumos de um setor $i$ são diretamente necessários para a produção final de $\mathrm{R} \$ 1,00$ do setor $j$.

Utilizando álgebra matricial, a equação 1 pode ser reescrita ao se isolar o vetor de demanda final $(y) \mathrm{e}$ colocar o vetor de produção $(x)$ em evidência: $(I-A) x=y$, onde $I$ é uma matriz identidade. Isolando para $x$, a solução única para o sistema de equações lineares é dada por:

$$
x=(I-A)^{-1}=L y
$$

Onde $(I-A)^{-1}=L$ representa a matriz inversa de Leontief ou a matriz de requerimentos totais. A equação 3 representa o valor bruto da produção necessária para suprir direta e indiretamente a demanda final da economia, no qual os coeficientes $l_{i j}$ da matriz $L$ podem ser interpretados como os impactos diretos e indiretos de um aumento unitário no valor da produção do setor $j$ sobre a produção do setor $i$. Como a matriz $A$ nada informa sobre os efeitos indiretos dos aumentos na produção de um setor, ou seja, da cadeia de impactos intersetoriais, a matriz $L$ se torna mais adequada à análise detalhada dos impactos de variações da demanda final. 
Para a construção de uma matriz de fluxo de tecnologia $H^{\prime}$, que descreve a transferência de tecnologia incorporada nas relações intermediárias entre os setores, utiliza-se o conceito de setores verticalmente integrados ou subsistemas. Neste caso, o gasto em P\&D é projetado na matriz de insumo-produto. Isto se dá pela pré-multiplicação de uma matriz diagonal de intensidade do gasto em P\&D setorial pela matriz de requerimentos técnicos diretos e indiretos (equação 3):

$$
H^{\prime}=\hat{r} \hat{x}^{-1} L \hat{y}
$$

Onde o sobrescrito " $\wedge "$ significa que o vetor foi transformado em uma matriz diagonal; $\hat{r}$ é a matriz diagonal de gasto em P\&D do setor $j$; e $\hat{x}^{-1}$ é a matriz diagonal inversa do valor bruto da produção do setor $j$, no qual $\hat{r} \hat{x}^{-1}=\frac{r_{j}}{x_{j}}$ representa a intensidade do gasto em P\&D do setor $j$. O termo $L \hat{y}$ representa a matriz cuja as colunas formam os "subsistemas" de uma economia. A soma dos elementos de uma coluna de $L \hat{y}$ contém toda a "cadeia produtiva" necessária para satisfazer a demanda final do setor $j$. Pré-multiplicando este termo por $\hat{r} \hat{x}^{-1}$, apresenta-se a matriz $H^{\prime}$, que realiza uma distribuição do gasto em P\&D sobre o sistema de produção de toda a economia, de modo que a soma de todos os seus elementos e a soma de todos os elementos de $r$ seja a mesma.

A matriz de fluxos de P\&D incorporada nas transações de bens e serviços apresentada pela equação 4, chamada a partir de agora de matriz de fluxos tecnológicos, é comumente denominada na literatura como uma matriz de "estrutura nominal" (actual-structure), pois a mesma incorpora a estrutura fornecida pela demanda final nominal das matrizes de insumo-produto. Alternativamente, pode-se negligenciar a informação disponível da demanda final da equação 4, dado por:

$$
H=\hat{r} \hat{x}^{-1} L
$$

Onde a matriz de fluxos tecnológicos $H$ representa as relações puramente tecnológicas do gasto em $\mathrm{P} \& \mathrm{D}$ incorporado em bens e serviços entre os setores econômicos, ou seja, na proporção da intensidade do gasto em $\mathrm{P} \& \mathrm{D}$ sobre os coeficientes técnicos diretos e indiretos da matriz $L$, não dependendo do tamanho e da estrutura da demanda final. Por este motivo, a matriz $H$ é comumente denominada na literatura como uma matriz de "estrutura padrão" (standard-structure). Essa abordagem possui a vantagem de analisar as ligações setoriais em proporções ditadas pelos coeficientes técnicos das matrizes, sem a necessidade de explicitar volumes dos valores econômicos (demanda final) sobre os gastos em P\&D representado pela matriz $H^{\prime}$.

Sob análise da estrutura padrão, cada célula de $H$ representa o gasto em P\&D incorporado em bens e serviços do setor $i$ necessária para satisfazer a demanda final do setor $j$. A soma das células de cada $i$ linha representa o total de $\mathrm{P} \& \mathrm{D}$ gasto por cada setor $i$. Extraindo-se os valores da diagonal principal de cada setor $i$, obtém-se o P\&D incorporado em bens e serviços transbordado (spillover) para outros setores a partir do gasto em P\&D do setor $i$. Já a soma das células de cada $j$ coluna representa o total de P\&D absorvido por meio da compra de bens e serviços por cada setor $j$. Extraindo-se os valores da diagonal principal de cada setor $j$, obtém-se o P\&D incorporado de outros setores para satisfazer sua demanda final. Sinteticamente:

$\sum_{i} h_{i j}$ : gasto total em P\&D do setor $i$ (soma da linha);

$\sum_{i} h_{i j}-h_{i j}^{0}$ : gasto em P\&D do setor $i$ transbordado (spillover) por meio da venda de bens e serviços para o setor $j$ (soma da linha menos a célula referente a diagonal principal: $h_{i j}^{0}$ );

$\sum_{j} h_{i j}$ : valor do P\&D incorporado na compra de bens e serviços absorvido pelo setor $j$ (soma da coluna);

$\sum_{j} h_{i j}-h_{i j}^{0}$ : gasto em P\&D incorporado na compra de bens e serviços pelo setor $j$ de outros setores da economia (soma da coluna menos a célula referente a diagonal principal: $h_{i j}^{0}$ ).

A mesma interpretação da matriz de fluxos tecnológicos diretos e indiretos $H$, com base nas transações interindustriais de consumo intermediário, pode ser analisada do ponto de vista das transações interindustriais diretas do próprio consumo intermediário. Nestes casos, a intensidade do gasto em $\mathrm{P} \& \mathrm{D}$ do setor $j\left(\hat{r} \hat{x}^{-1}\right)$ é 
pré-multiplicada pelo coeficiente técnico direto, respectivamente, de consumo intermediário $(A)$ e de investimento $(B)$. Forma-se, assim, as matrizes de fluxos tecnológicos $M$ e $K$, onde os gastos em P\&D são incorporados, respectivamente, na compra e venda direta de insumos intermediários e de bens de capital:

$$
\begin{aligned}
& M=\hat{r} \hat{x}^{-1} A \\
& K=\hat{r} \hat{x}^{-1} B
\end{aligned}
$$

As interpretações dadas pelos coeficientes das matrizes $H, M$ e $K$ fornecem um quadro rigoroso para a análise da interdependência do sistema produtivo, no qual contempla toda a economia de um país. No entanto, como analisado por Marengo e Sterlacchini (1990), por se tratar da complexidade do processo de difusão da tecnologia, algumas hipóteses simplificadoras deste modelo devem ser ressaltadas: i) todos os gastos em P\&D são supostos de serem incorporados em bens de consumo intermediário e bens de capital produzidos, no qual nenhum outro tipo de transferência ou proximidade tecnológica é considerado; ii) a incorporação do gasto em P\&D de um setor por outro é assumida de forma completa e instantânea: não há nenhuma consideração sobre o fato de nenhuma ou só um estágio mais avançado de esforço de P\&D gerarem melhorias em algum bem produzido; e iii) o modelo não prevê que a diversificação tecnológica pode ser maior e diferencialmente distribuída do que a diversificação da produção de uma análise de insumo-produto em si, isto é, firmas que estão envolvidas em atividades de P\&D nas áreas em que não são (na mesma medida) economicamente ativas.

Essas limitações podem ser melhor conceituadas de acordo com fontes distintas de externalidades (spillovers) geradas pelo esforços de P\&D. Para Griliches (1979), por exemplo, há dois tipos básicos de spillover: rent-spillover e o knowledge-spillover. O rent-spillover está relacionado com os ganhos de produtividade dos setores usuários de inovações por meio da compra de insumos produtivos novos ou melhorados fornecidos pelos setores produtores, ou seja, por meio das transações de compra e venda de bens e serviços de uma economia. É este spillover que se busca mensurar por meio das matrizes de fluxos tecnológicos $H, M$ e $K$. No entanto, as externalidades trazidas pela tecnologia vão além das transações econômicas observáveis, no qual o knowledge-spillover seria o transbordamento do conhecimento não incorporado na compra e venda de bens e serviços, e sim na difusão do conhecimento tácito, como ideias, habilidades, expertise ou até mesmo de arranjos cooperativos para inovação de setores com proximidade tecnológica, mas que não necessariamente transacionam mercadorias entre si.

Dessa maneira, deve-se ressaltar as limitações do quadro de fluxos tecnológicos intersetoriais proposto neste artigo: gastos em P\&D incorporados nos bens e serviços transacionados entre os setores econômicos.

\subsection{Base de dados}

A base de dados para a construção das matrizes de fluxos tecnológicos para o Brasil apresentada na subseção anterior exige a compatibilização de quatro fontes de dados secundárias: i) matrizes de insumoproduto (MIP), disponibilizadas pelo IBGE a cada cinco anos; ii) estimações das MIPs entre os anos 2000 e 2014, estimadas e disponibilizadas por Passoni e Freitas (2017) e Passoni (2018, no prelo), com base nos dados das MIPs e do Sistema de Contas Nacionais (SCN), também do IBGE; iii) Matrizes de Absorção de Investimentos (MAI), estimadas e disponibilizadas por Miguez (2016), também com base nos dados do SCN para os anos entre 2000 e 2013; e iv) dados de P\&D em níveis setoriais, disponibilizados pelo IBGE por meio da Pesquisa de Inovação (Pintec), disponível para os anos 2000, 2003, 2005, 2008, 2011 e 2014. Os maiores problemas de compatibilização dos dados se referem a abrangência da série de anos disponíveis, divergências nas classificações de atividades econômicas, e, para o caso das matrizes de insumo-produto, mudanças de metodologias de cálculo ao longo de sua série.

As matrizes de insumo-produto para a economia brasileira são calculadas pelo IBGE e têm sido divulgadas a cada cinco anos para os anos com finais zero e cinco. A última MIP disponibilizada é para o ano de 2010. Como os dados de P\&D estão disponíveis apenas a partir de 2000, as MIPs originais disponíveis para este estudo se restringem aos períodos 2000, 2005 e 2010. Na tentativa de preencher as lacunas dos anos para 
as quais as MIPs não são divulgadas oficialmente, existem algumas técnicas de estimação e atualização das matrizes com base em informações adicionais, advindas das tabelas de recursos e usos (TRUs), do Sistema de Contas Nacionais (SCN), divulgados periodicamente pelo IBGE. No Brasil, alguns autores como Guilhoto e Sesso Filho (2005), Grijó e Bêrni (2006) e Martinez (2015) propuseram alguns métodos de estimação das matrizes brasileiras.

Para este artigo, optou-se por utilizar as estimações propostas e disponibilizadas por Passoni e Freitas (2017) e Passoni (2018, no prelo), em metodologia sugerida por Grijó e Bêrni (2006). Esta metodologia consiste na utilização das informações estruturais presentes nas MIPs oficiais com dados anuais disponíveis das TRUs e é descrita com detalhes em Passoni e Freitas (2017). De maneira geral, o método consiste em gerar informações estruturais (mark-downs) das MIPs originais, criando proporções que serão preenchidas pelos dados contidos nas TRUs de cada ano que se deseja estimar. Técnicas de ajustes e balanceamento das matrizes também foram realizadas por meio do método de ajustamento RAS ${ }^{5}$, tornando as informações das TRUs compatíveis com as estruturas das MIPs.

No entanto, a compatibilização de uma série completa de matrizes insumo-produto possivelmente estimadas entre 2000 e 2014 ainda apresenta dificuldades devido à mudança de metodologia de cálculo das TRUs realizadas pelo IBGE durante este período. Entre os anos 2000 e 2009 as TRUs utilizaram como base de cálculo o SCN referência 2000, enquanto os dados a partir de 2010 seguem o método do SCN referência 2010. Dentre as principais mudanças se encontram uma nova classificação de atividades econômicas (setores), passando da Classificação Nacional de Atividades Econômicas (CNAE) 1.0 para 2.0, mudanças no cálculo da Formação Bruta de Capital Fixo (FBCF), e mudanças nas pesquisas básicas estruturantes (IBGE, 2015).

Para a compatibilização de uma série completa entre 2000 e 2014 estimada e disponibilizada por Passoni (2018, no prelo), a mesma criou um tradutor para adequar a classificação das atividades econômicas divergentes entre as matrizes. Essa agrupação forneceu uma estrutura de 42 atividades por 91 produtos ajustada para os anos 2000 a 2014. No entanto, para ainda ser compatível com os dados fornecidos pela Pintec e pelas MAIs, as MIPs chegaram a uma estrutura final de 35 setores por 91 produtos. Com as técnicas de transformação em matrizes quadradas necessárias para o modelo insumo-produto, chega-se a estrutura final de matrizes 35x35 para os anos 2000, 2003, 2005, 2008, 2011 e 2014, que são os anos nos quais dados de P\&D setoriais estão disponíveis pela Pintec. Os detalhes das agregações setoriais por códigos de CNAE e SCN são apresentadas na Tabela A1, no Anexo.

Por fim, cabe ressaltar que as matrizes foram deflacionadas a preços do ano 2000 por meio de índices de preços por produto presente nas TRUs. Já os dados de gastos em P\&D foram deflacionados para o ano base de 2000 por meio do Índice de Preços ao Produtor Amplo (IPA), mensurado pela Fundação Getulio Vargas.

\subsection{Modelo econométrico}

A estimação econométrica entre os fluxos de tecnologia intersetorial e a produtividade dos setores da economia brasileira é realizada por meio de modelos de dados em painel dinâmico. Os modelos são estimados pelo Método dos Momentos Generalizados (GMM), nas especificações desenvolvidas por Arellano e Bond (1991), Arellano e Bover (1995) e Blundell e Bover (1998). A principal caraterística e vantagem desse método de estimação em painel é a possibilidade do uso de variáveis explicativas defasadas como endógenas, utilizando-as como instrumentos. Contorna-se, assim, possíveis problemas de endogeneidade entre as variáveis estimadas. Técnicas de estimadores GMM (difference e system), testes estatísticos de validade dos instrumentos (teste de Hansen e diferença de Hansen) e testes de ausência de autocorrelação (AR2) também foram analisados para validar a consistência dos modelos. Detalhes desses métodos e testes podem ser verificados em Roodman (2009).

\footnotetext{
${ }^{5} \mathrm{O}$ método RAS é uma técnica de ajustamento biproporcional entre matrizes, amplamente utilizada nas atualizações de matrizes insumo-produto (MILLER; BLAIR, 2009). Passoni e Freitas (2017) utilizaram a técnica de RAS generalizado, denominado na literatura como GRAS, com base em Temurshoev, Miller e Bouwmeester (2013).
} 
Os efeitos dos esforços inovativos (P\&D próprio e P\&D incorporado nos bens de consumo e de capital) sobre a produtividade dos setores da economia brasileira são estimados por meio da base de dados apresentada na subseção anterior. Há algumas limitações da série entre os anos 2000 e 2014, principalmente no que se refere aos dados de P\&D. Como esses dados são provenientes da Pintec, os fluxos tecnológicos são estimados apenas para os anos 2000, 2003, 2005, 2008, 2011 e 2014, enquanto os dados de produtividade são extraídos das matrizes de insumo-produto a 35 setores estimadas entre 2000 e 2014.

Alguns estudos empíricos já mostraram que os esforços em P\&D demoram alguns anos para surtirem efeito no desempenho produtivo de empresas (e.g. RAVENSCRAFT e SCHERER, 1982; GEROSKI, 1991). Dessa maneira, como o objetivo é estimar os efeitos dos esforços inovativos sobre a taxa de crescimento da produtividade, o ano de 2014 é descartado, já que se deve verificar o impacto da inovação sobre anos posteriores, no qual ainda não há MIPs disponíveis. Isso também é reforçado pelo fato das matrizes de absorção de investimentos (MAIs), utilizadas para dados de investimentos e P\&D incorporado nos bens de capital, estarem disponíveis apenas para o período entre 2000 e 2013.

Outra caraterística da Pintec é que, ao contrário de todas as suas publicações que são elaboradas a cada três anos, a Pintec 2005 tem uma diferença temporal de 2 anos em relação a sua antecessora. Dessa maneira, para manter uma padronização, optou-se por verificar os efeitos dos esforços inovativos sobre a taxa de crescimento da produtividade a cada dois anos. Por exemplo, os efeitos dos esforços inovativos de 2000 sobre a taxa de crescimento da produtividade entre 2000 e 2002 até chegar nos efeitos dos esforços inovativos de 2011 sobre a taxa de crescimento da produtividade entre 2011 e 2013 . Totaliza-se, assim, um modelo em painel de 5 períodos no tempo.

No entanto, a maior limitação da amostra disponível se refere aos setores contemplados pela Pintec. Apenas a indústria de transformação e a indústria extrativa apresentam dados de gastos em P\&D para todos os anos. Já os serviços de comunicação e informação e os serviços de engenharia, testes e P\&D são contemplados a partir de 2005, enquanto os serviços industriais de utilidade pública (SIUP) apenas a partir de 2011. Dessa maneira, dos 35 setores disponíveis, apenas 25 possuem dados de gastos em P\&D. Dado esse problema, a estratégia de estimação levou em consideração dois conjuntos de amostras: i) amostra de setores com dados próprios de $\mathrm{P} \& \mathrm{D}$, que contempla toda a indústria de transformação, a indústria extrativa e alguns anos dos serviços de comunicação e informação, serviços de engenharia, testes e P\&D e SIUP; e ii) amostra total, que além desses, também contempla a agropecuária, a construção civil e os demais serviços (maioria voltados para a demanda final: educação, saúde, etc. - Ver Tabela A1, no Anexo).

Como as estimações abrangem cinco períodos no tempo, isso faz com que a primeira amostra atinja um número de 117 observações e a segunda um número de 175 observações, consideradas baixas para estimações econométricas, mas possíveis de serem estimadas e avaliadas em testes estatísticos. Na primeira amostra é possível verificar o impacto tanto do $\mathrm{P} \& \mathrm{D}$ próprio, quanto dos fluxos tecnológicos intersetoriais, sobre a produtividade, enquanto na segunda amostra é possível verificar apenas o impacto dos fluxos tecnológicos. Pode-se hipotetizar que os setores em que não há dados de esforços inovativos disponíveis, ou seja, que não são contemplados pela Pintec, não investem ou investem muito pouco em P\&D. No entanto, manter um valor igual zero para essa variável em uma amostra total, além de muito restritivo, não é possível no tipo de estimação econométrica proposta.

Por fim, ressalta-se que não há dados de estoque de capital em nível setorial para a economia brasileira, o que impede uma mensuração da produtividade total dos fatores. Logo, utiliza-se a mensuração da produtividade do trabalho, calculada pelo valor bruto da produção (VBP) sobre o número de trabalhadores. Para um melhor ajustamento do modelo estatístico, utiliza-se também uma medida de taxa de crescimento do investimento como regressor, calculado pelo valor da formação bruta de capital fixo (FBCF) pelo número de trabalhadores. Espera-se, neste caso, que o efeito da taxa de crescimento do investimento sobre a taxa de crescimento da produtividade do trabalho seja positivo.

O modelo da relação entre esforço inovativo ( $\mathrm{P} \& \mathrm{D}$ próprio e $\mathrm{P} \& \mathrm{D}$ incorporadas nos bens de consumo e de capital) e produtividade dos setores da economia brasileira é representado pela equação 8: 


$$
\Delta \ln \left(\text { Produt }_{i, t}\right)=\beta_{1} \ln \left(\text { Produt }_{i t_{0}}\right)+\beta_{2} \Delta \ln \left(\text { Invest }_{i t}\right)+\beta_{3} \ln \left(\text { Inov }_{i t_{0}}\right)+\beta_{4} D+\eta_{i}+\mu_{i t}
$$

Onde:

$i=1,2, \ldots, 25$ ou 35 setores.

$t=1,2, \ldots, 5$ períodos de tempo. Taxas de crescimento $(\Delta)$ de dois em dois anos: 2000-2002, 20032005, 2005-2007, 2008-2010 e 2011-2013. Períodos iniciais $\left(t_{0}\right):$ 2000, 2003, 2005, 2008 e 2011.

$D=$ Dummies temporais;

$\Delta \ln \left(\right.$ Produt $\left._{i, t}\right):$ taxa de crescimento em logaritmo da produtividade do trabalho, representado pelo valor bruto da produção pelo número de pessoal ocupado.

$\ln \left(\right.$ Produt $\left._{i t_{0}}\right)$ : logaritmo da produtividade do trabalho no período inicial. Analisa-se se setores com maiores níveis de produtividade do trabalho apresentam maiores taxas de crescimento da mesma variável. Setores com altos níveis de produtividade do trabalho geralmente são mais intensivos em capital, como, por exemplo, a indústria extrativa mineral. Um valor negativo do coeficiente dessa variável poderia indicar que setores com maiores níveis de produtividade do trabalho possuam retornos marginais decrescentes de capital, enquanto que um sinal positivo representaria retornos marginais crescentes de capital.

$\Delta \ln \left(\right.$ Invest $\left._{i t}\right)$ : taxa de crescimento em logaritmo da FBCF sobre o número de pessoal ocupado;

$\ln \left(\operatorname{Inov}_{i t_{0}}\right)$ : conjunto de proxies de esforços inovativos baseados em P\&D no período inicial. As variáveis de esforços inovativos buscam testar tanto os efeitos dos gastos em P\&D próprio dos setores sobre a sua produtividade, que é a abordagem padrão utilizada na grande maioria dos trabalhos empíricos, quanto os efeitos de P\&D incorporados em bens de consumo intermediário (matrizes $\mathrm{M} \mathrm{e} \mathrm{H}$ ) e bens de capital (matriz K). São sete variáveis de esforços inovativos:

a) $P \& D$ Próprio: Intensidade do gasto em $\mathrm{P} \& \mathrm{D}\left(\frac{P \& D}{V B P}\right)$;

b) $P \& D$ Absorvido $A$ : Intensidade dos gastos em $\mathrm{P} \& \mathrm{D}$ totais absorvidos (intra e intersetorial) diretamente em bens de consumo intermediário por meio da matriz $\mathrm{A}$ de coeficientes técnicos $\left(\sum_{j} m_{i j}=\right.$ $\left.\hat{r} \hat{x}^{-1} A\right)$

c) $P \& D$ Intersetorial $A$ : Intensidade dos gastos em $P \& D$ absorvidos de outros setores (intersetorial) diretamente em bens de consumo intermediário por meio da matriz A de coeficientes técnicos $\left(\sum_{j} m_{i j}-m_{i j}^{0}=\right.$ $\left.\hat{r} \hat{x}^{-1} A^{0}\right)$

d) $P \& D$ Absorvido $L$ : Intensidade dos gastos em P\&D totais absorvidos (intra e intersetorial) direta e indiretamente em bens de consumo intermediário por meio da matriz L de Leontief $\left(\sum_{j} h_{i j}=\hat{r} \hat{x}^{-1} L\right)$;

e) $P \& D$ Intersetorial $L$ : Intensidade dos gastos em P\&D absorvidos de outros setores (intersetorial) direta e indiretamente em bens de consumo intermediário por meio da matriz L de Leontief $\left(\sum_{j} h_{i j}-h_{i j}^{0}=\right.$ $\left.\hat{r} \hat{x}^{-1} L^{0}\right)$

f) $P \& D$ Absorvido $B$ : Intensidade dos gastos em $P \& D$ totais absorvidos (intra e intersetorial) diretamente em bens de capital por meio da matriz B de coeficientes técnicos de investimentos $\left(\sum_{j} k_{i j}=\right.$ $\left.\hat{r} \hat{x}^{-1} B\right)$

g) $P \& D$ Intersetorial $B$ : Intensidade dos gastos em $\mathrm{P} \& \mathrm{D}$ absorvidos de outros setores (intersetorial) diretamente em bens de capital por meio da matriz B de coeficientes técnicos de investimentos $\left(\sum_{j} k_{i j}-k_{i j}^{0}=\right.$ $\left.\hat{r} \hat{x}^{-1} B^{0}\right)$.

Todas as variáveis são consideradas endógenas no modelo, com a utilização de suas defasagens como instrumentos. Preferiu-se não inserir a variável dependente defasada entre os regressores para não perder um número maior de observações, no entanto, como é caraterístico dos modelos em painel dinâmico, as suas defasagens também são utilizadas como instrumentos para controlar o viés de endogeneidade. As Tabelas A2 e A3 no Anexo apresentam, respectivamente, os detalhes das variáveis da amostra por meio de algumas estatísticas descritivas e teste de correlação. 


\section{Resultados}

A Tabela 1 apresenta os resultados das estimações econométricas de painel dinâmico GMM system sobre a relação entre as variáveis de $\mathrm{P} \& \mathrm{D}$ e taxa de crescimento da produtividade do trabalho para a amostra de setores que possuem dados de P\&D próprio. Estimou-se um total de doze modelos: um para cada uma das sete variáveis de $\mathrm{P} \& \mathrm{D}$ de interesse, e cinco modelos com as variáveis de $\mathrm{P} \& \mathrm{D}$ próprio e $\mathrm{P} \& \mathrm{D}$ intersetorial em conjunto. Dada a alta correlação entre P\&D próprio e P\&D absorvido total (Ver Tabela A3 no Anexo), modelos estimados com esses dois tipos de variáveis foram descartados devido a um provável problema de multicolinearidade. Na parte inferior da tabela são apresentados os p-valores dos testes de autocorrelação AR (2), e de validade dos instrumentos (Teste de Hansen e Teste de diferença de Hansen). Para todos os modelos, os p-valores foram altos acima de 10\%, portanto, aceita-se a hipótese nula de ausência de correlação serial de segunda ordem, confirmando a consistência das estimações; e aceita-se a hipótese nula de que o conjunto dos instrumentos são válidos e não correlacionados com o termo de erro, eliminando-se o viés de endogeneidade. $\mathrm{O}$ teste de diferença de Hansen ainda indica que o método GMM system é mais adequado do que o método GMM difference. Dessa maneira, as estimações por este último método não foram reportadas.

Antes da análise das variáveis de $\mathrm{P} \& \mathrm{D}$, as estimações mostraram para todos os modelos um sinal negativo para a variável de produtividade inicial, ou seja, que em média os setores com os menores níveis de produtividade apresentaram uma maior variação da produtividade do trabalho. Este tipo de resultado poderia indicar algum grau de convergência da produtividade entre os setores por meio da hipótese de retornos marginais decrescentes de capital. No entanto, essa variável foi estatisticamente significativa apenas para os modelos 2 e 4, além de possuírem valores muito baixos de seus coeficientes. Dessa maneira, não se pode verificar uma relação causal entre o nível e a taxa de crescimento da produtividade do trabalho para o período de análise. Já a taxa de crescimento do investimento por trabalhador possui um efeito positivo e estatisticamente significativo à $1 \%$ com a produtividade do trabalho para todos os modelos. A taxa de retorno dos investimentos sobre a produtividade girou em torno $5,6 \%$ a 9,4\% em média dependendo da especificação do modelo. Este resultado era esperado, dada a importância dos investimentos para a produtividade e o crescimento econômico.

Com relação às variáveis de interesse de $\mathrm{P} \& \mathrm{D}$ e $\mathrm{P} \& \mathrm{D}$ incorporado, verifica-se que, com exceção da variável "P\&D intersetorial A" no modelo 11, as mesmas apresentaram sinais positivos e estatisticamente significativos para todos os modelos (a grande maioria a 1\%). A Tabela 1 mostra ainda que, em média, para os modelos estimados separadamente, o retorno das variáveis de P\&D incorporado em bens de consumo intermediário de outros setores sobre a produtividade foram maiores do que o retorno do $\mathrm{P} \& \mathrm{D}$ próprio. Enquanto o coeficiente de $\mathrm{P} \& \mathrm{D}$ próprio apresentou um valor de 5,7\%, os coeficientes de $\mathrm{P} \& \mathrm{D}$ intersetorial A e intersetorial $\mathrm{L}$ apresentaram, respectivamente, valores de 7,4\% e 6,2\%. Os coeficientes de P\&D total absorvidos A e L apresentaram retornos ainda maiores (9,1\% e 10,4\%, respectivamente), já que os mesmos levam em consideração não apenas o P\&D intersetorial, como também o P\&D incorporado intrasetorialmente. As estimações não mostraram uma distinção muito clara das variáveis de $\mathrm{P} \& \mathrm{D}$ incorporado por meio das matrizes de coeficientes técnicos diretos A e diretos e indiretos $\mathrm{L}$.

As variáveis de $\mathrm{P} \& \mathrm{D}$ incorporado nos bens de capital também apresentaram retornos positivos e estatisticamente significativos a $1 \%$ sobre a produtividade. No entanto, os valores dos coeficientes foram menores do que as outras variáveis de P\&D. Inicialmente, esperava-se que o P\&D incorporado em bens de capital fossem ainda mais importantes para o crescimento da produtividade do que o P\&D incorporado em bens de consumo. Isso pode ser explicado pelo fato de que as transferências de capital estão restritas a poucos setores, principalmente máquinas e equipamentos, que no Brasil investem proporcionalmente menos em P\&D do que setores chaves do ponto de vista das transferências de insumos de produção, como a indústria química e de refino de petróleo (IBGE, 2016). 
Tabela 1 - Estimações painel dinâmico GMM system, Amostra setores com dados de P\&D - Variável dependente: crescimento da produtividade do trabalho

\begin{tabular}{|c|c|c|c|c|c|c|c|c|c|c|c|c|}
\hline & (1) & (2) & (3) & (4) & (5) & (6) & (7) & (8) & (9) & (10) & (11) & (12) \\
\hline Produt $_{\text {to }}$ & $\begin{array}{l}-0,015 \\
(0,016)\end{array}$ & $\begin{array}{l}-0,040 * * \\
(0,014)\end{array}$ & $\begin{array}{l}-0,004 \\
(0,016)\end{array}$ & $\begin{array}{l}-0,030 * * \\
(0,011)\end{array}$ & $\begin{array}{l}-0,016 \\
(0,017)\end{array}$ & $\begin{array}{l}-0,024 \\
(0,018)\end{array}$ & $\begin{array}{l}-0,025 \\
(0,018)\end{array}$ & $\begin{array}{l}-0,005 \\
(0,016)\end{array}$ & $\begin{array}{l}-0,001 \\
(0,016)\end{array}$ & $\begin{array}{l}-0,007 \\
(0,018)\end{array}$ & $\begin{array}{l}-0,014 \\
(0,012)\end{array}$ & $\begin{array}{l}-0,038 \\
(0,026)\end{array}$ \\
\hline$\Delta$ Invest & $\begin{array}{l}0,056 * * * \\
(0,011)\end{array}$ & $\begin{array}{l}0,060 * * * \\
(0,013)\end{array}$ & $\begin{array}{l}0,071 * * * \\
(0,015)\end{array}$ & $\begin{array}{l}0,070 * * * \\
(0,014)\end{array}$ & $\begin{array}{l}0,075 * * * \\
(0,015)\end{array}$ & $\begin{array}{l}0,080 * * * \\
(0,017)\end{array}$ & $\begin{array}{l}0,080 * * * \\
(0.017)\end{array}$ & $\begin{array}{l}0,069 * * * \\
(0,010)\end{array}$ & $\begin{array}{l}0,077 * * * \\
(0,011)\end{array}$ & $\begin{array}{l}0,094 * * * \\
(0,013)\end{array}$ & $\begin{array}{l}0,077 * * * \\
(0,074)\end{array}$ & $\begin{array}{l}0,081 * * * \\
(0,011)\end{array}$ \\
\hline \multicolumn{13}{|l|}{$P \& D_{\text {to }}$} \\
\hline Próprio & $\begin{array}{l}0,057 * * * \\
(0,015)\end{array}$ & & & & & & & $\begin{array}{l}0,054 * * * \\
(0,013)\end{array}$ & $\begin{array}{l}0,051 * * * \\
(0,013)\end{array}$ & $\begin{array}{l}0,053 * * * \\
(0,014)\end{array}$ & $\begin{array}{l}0,061 * * * \\
(0,013)\end{array}$ & $\begin{array}{l}0,052 * * * \\
(0,011)\end{array}$ \\
\hline Abs A & & $\begin{array}{l}0,091 * * * \\
(0,023)\end{array}$ & & & & & & & & & & \\
\hline Inter A & & & $\begin{array}{l}0,074 * * * \\
(0,020)\end{array}$ & & & & & $\begin{array}{l}0,055^{*} * \\
(0,021)\end{array}$ & & & $\begin{array}{l}0,024 \\
(0,015)\end{array}$ & \\
\hline Abs L & & & & $\begin{array}{l}0,104 * * * \\
(0,019)\end{array}$ & & & & & & & & \\
\hline Inter L & & & & & $\begin{array}{l}0,062 * * \\
(0,023)\end{array}$ & & & & $\begin{array}{l}0,077 * * * \\
(0,022)\end{array}$ & & & $\begin{array}{l}0,061 * * \\
(0,026)\end{array}$ \\
\hline Abs B & & & & & & $\begin{array}{l}0,034 * * * \\
(0,010)\end{array}$ & & & & & & \\
\hline Inter B & & & & & & & $\begin{array}{l}0,031 * * * \\
(0,010)\end{array}$ & & & $\begin{array}{l}0,044 * * * \\
(0,010)\end{array}$ & $\begin{array}{l}0,024 * * * \\
(0,008)\end{array}$ & $\begin{array}{l}0,015 * * \\
(0,008)\end{array}$ \\
\hline AR (2) & 0,913 & 0,166 & 0,169 & 0,196 & 0,155 & 0,513 & 0,550 & 0,413 & 0,352 & 0,431 & 0,424 & 0,571 \\
\hline Hansen & 0,119 & 0,246 & 0,295 & 0,397 & 0,318 & 0,173 & 0,166 & 0,319 & 0,392 & 0,553 & 0,472 & 0,366 \\
\hline Dif Hansen & 0,930 & 0,156 & 0,568 & 0,236 & 0,452 & 0,116 & 0,062 & 0,423 & 0,524 & 0,208 & 0,278 & 0,198 \\
\hline $\mathrm{N}^{\mathrm{o}}$ inst. & 19 & 19 & 19 & 19 & 19 & 19 & 19 & 21 & 21 & 21 & 26 & 26 \\
\hline $\mathrm{N}^{\mathrm{o}}$ obs. & 117 & 117 & 117 & 117 & 117 & 117 & 117 & 117 & 117 & 117 & 117 & 117 \\
\hline $\mathrm{N}^{\circ}$ setores & 25 & 25 & 25 & 25 & 25 & 25 & 25 & 25 & 25 & 25 & 25 & 25 \\
\hline
\end{tabular}

Nota: Os símbolos *, ** e *** indicam p-valores menores do que 10\%, $5 \%$ e 1\%, respectivamente. Erros-padrão robustos em parênteses. São reportados os pvalores das estatísticas de teste AR (2), Teste de Hansen e Teste de diferença de Hansen para os instrumentos GMM em nível. Variáveis dependente e explicativas se encontram em logaritmos (ln). Dummies temporais e constante foram estimadas nos modelos e não estão reportadas. Os modelos estimados foram realizados a partir do comando "xtabond2" do software Stata 14, desenvolvido por Roodman (2009), e controlam para o excesso de instrumentos (comandos "laglimits" ou “collapse”), possuem ajustes para amostras pequenas (comando "small”) e desvios ortogonais (comando "orthogonal"). Estimação GMM system em dois estágios. Fonte: elaboração própria. 
Para os modelos em que a variável de $\mathrm{P} \& \mathrm{D}$ próprio foi estimada em conjunto com um tipo de $\mathrm{P} \& \mathrm{D}$ intersetorial (modelos 8,9 e 10), verifica-se que os valores dos coeficientes se mantiveram mais ou menos iguais para todas as variáveis. Pôde-se perceber um coeficiente um pouco menor para o $\mathrm{P} \& \mathrm{D}$ intersetorial A, mas um pouco maiores para o P\&D intersetorial L e B. Já os modelos 11 e 12, que inserem dois tipos de $P \& D$ intersetorial, mostraram-se menos adequados, já que o $P \& D$ intersetorial A perde sua significância estatística, enquanto que os coeficientes das outras variáveis diminuem seus valores. Esses últimos resultados podem indicar problemas de colinearidade entre as variáveis explicativas de P\&D intersetorial. Nessas especificações, porém, persiste-se um impacto do $\mathrm{P} \& \mathrm{D}$ intersetorial $\mathrm{L}$ sobre a produtividade do trabalho maior do que o $\mathrm{P} \& \mathrm{D}$ próprio, dando maior destaque aos fluxos tecnológicos incorporados direta e indiretamente.

Os resultados da Tabela 1 indicam os impactos dos fluxos tecnológicos para os setores que em tese investem ou são mais representativos em P\&D, compreendendo toda a indústria (menos construção) e os serviços mais intensivos em conhecimento. Por outro lado, a Tabela 2 apresenta os resultados das estimações econométricas de painel dinâmico GMM system sobre a relação entre as variáveis de $P \& D$ e taxa de crescimento da produtividade do trabalho para a amostra total da economia. Neste caso, são acrescentados a agropecuária, a construção civil e, principalmente, os demais serviços. Como não há dados de P\&D próprio desses setores, a mesma é descartada da estimação. Na parte inferior da tabela, apresenta-se os testes de autocorrelação e de validade dos instrumentos. Mais uma vez, todos os modelos apresentaram p-valores acima de $10 \%$ para estes testes, o que valida a consistência e o conjunto de instrumentos utilizados.

Tabela 2 - Estimações painel dinâmico GMM system, Amostra total - Variável dependente: crescimento da produtividade do trabalho

\begin{tabular}{|c|c|c|c|c|c|c|c|c|}
\hline & $(1)$ & $(2)$ & (3) & $(4)$ & (5) & (6) & $(7)$ & $(8)$ \\
\hline Produt $_{\text {to }}$ & $\begin{array}{c}0,013 \\
(0,012)\end{array}$ & $\begin{array}{c}0,011 \\
(0,008)\end{array}$ & $\begin{array}{c}0,010 \\
(0,009)\end{array}$ & $\begin{array}{c}0,003 \\
(0,007)\end{array}$ & $\begin{array}{c}0,022 * * * \\
(0,003)\end{array}$ & $\begin{array}{c}0,024 * * * \\
(0,004)\end{array}$ & $\begin{array}{c}0,005 \\
(0,007)\end{array}$ & $\begin{array}{c}0,007 \\
(0,005)\end{array}$ \\
\hline$\Delta$ Invest & $\begin{array}{c}0,052 * * * \\
(0,006)\end{array}$ & $\begin{array}{c}0,052 * * * \\
(0,007)\end{array}$ & $\begin{array}{c}0,047 * * * \\
(0,004)\end{array}$ & $\begin{array}{c}0,049 * * * \\
(0,007)\end{array}$ & $\begin{array}{c}0,049 * * * \\
(0,005)\end{array}$ & $\begin{array}{c}0,050 * * * \\
(0,005)\end{array}$ & $\begin{array}{c}0,039 * * * \\
(0,004)\end{array}$ & $\begin{array}{c}0,042 * * * \\
(0,004)\end{array}$ \\
\hline $\begin{array}{l}\mathbf{P} \& \mathbf{D} \text { to } \\
\text { Abs A }\end{array}$ & $\begin{array}{c}0,021 * * \\
(0,008)\end{array}$ & & & & & & & \\
\hline Inter A & & $\begin{array}{c}0,030 * * * \\
(0,009)\end{array}$ & & & & & $\begin{array}{c}0,015^{* * *} * \\
(0,003)\end{array}$ & \\
\hline Abs L & & & $\begin{array}{c}0,009 * * \\
(0,004)\end{array}$ & & & & & \\
\hline Inter L & & & & $\begin{array}{c}0,023 * * \\
(0,010)\end{array}$ & & & & $\begin{array}{c}0,006 \\
(0,005)\end{array}$ \\
\hline Abs B & & & & & $\begin{array}{c}0,011 * * * \\
(0,003)\end{array}$ & & & \\
\hline Inter B & & & & & & $\begin{array}{c}0,012 * * * \\
(0,003)\end{array}$ & $\begin{array}{c}0,002 \\
(0,003)\end{array}$ & $\begin{array}{c}0,005 * * \\
(0,002)\end{array}$ \\
\hline AR (2) & 0,914 & 0,949 & 0,550 & 0,853 & 0,938 & 0,956 & 0,903 & 0,820 \\
\hline Hansen & 0,200 & 0,269 & 0,387 & 0,176 & 0,356 & 0,358 & 0,663 & 0,148 \\
\hline Dif Hansen & 0,634 & 0,663 & 0,627 & 0,484 & 0,678 & 0,676 & 0,849 & 0,228 \\
\hline $\mathrm{N}^{\mathrm{o}}$ inst. & 25 & 25 & 25 & 25 & 33 & 33 & 41 & 41 \\
\hline $\mathrm{N}^{\mathrm{o}}$ obs. & 175 & 175 & 175 & 175 & 175 & 175 & 175 & 175 \\
\hline $\mathrm{N}^{\mathrm{o}}$ setores & 35 & 35 & 35 & 35 & 35 & 35 & 35 & 35 \\
\hline
\end{tabular}

Nota: Os símbolos *,** e *** indicam p-valores menores do que 10\%, 5\% e 1\%, respectivamente. Erros-padrão robustos em parênteses. São reportados os p-valores das estatísticas de teste AR (2), Teste de Hansen e Teste de diferença de Hansen para os instrumentos GMM em nível. Variáveis dependente e explicativas se encontram em logaritmos (ln). Dummies temporais e constante foram estimadas nos modelos e não estão reportadas. Os modelos estimados foram realizados a partir do comando "xtabond2" do software Stata 14, desenvolvido por Roodman (2009), e controlam para o excesso de instrumentos (comandos "laglimits" ou "collapse"), possuem ajustes para amostras pequenas (comando "small") e desvios ortogonais (comando "orthogonal"). Estimação GMM system em dois estágios.

Fonte: elaboração própria. 
A Tabela 2 mostra que, no geral, as variáveis de P\&D incorporado apresentaram uma relação positiva e estatisticamente significativa com a produtividade do trabalho. Nos modelos 7 e 8 , no qual são inseridos mais de um tipo de $\mathrm{P} \& \mathrm{D}$ intersetorial, elimina-se a significância estatística de algum deste, muito provavelmente devido ao problema de colinearidade. No entanto, numa comparação com os resultados da Tabela 1, a Tabela 2 mostra que todos os coeficientes apresentaram valores menores, ou seja, os fluxos tecnológicos, em média, impactam positivamente a produtividade de todos os setores da economia, mas numa intensidade menor do que nos setores industriais e nos serviços mais intensivos em conhecimento. Esse resultado era esperado, pois dos dez setores acrescentados na análise, oito pertencem a serviços que em sua maioria são voltados para a demanda final.

Analisando-se de maneira geral os fluxos de P\&D incorporado nas Tabelas 1 e 2, os resultados foram aqueles esperados: não só o $\mathrm{P} \& \mathrm{D}$ próprio dos setores industrias são importantes para explicar uma maior taxa de crescimento da produtividade do trabalho, como também os fluxos tecnológicos são relevantes para o aumento da produtividade dos setores de toda a economia. Se o P\&D intersetorial é mais importante do que o $\mathrm{P} \& \mathrm{D}$ próprio é uma questão mais delicada, já que os valores dos coeficientes foram relativamente próximos entre as distintas variáveis de P\&D. Pelos resultados dos modelos estimados, parece que os fluxos tecnológicos intersetoriais baseados em P\&D de bens de consumo têm um peso maior para o crescimento da produtividade no Brasil do que os fluxos intersetoriais de capital.

Esses resultados foram semelhantes às pesquisas que estimaram fluxos tecnológicos e produtividade, apesar das significativas diferenças de métodos de estimação. Dentre os trabalhos mais relevantes que abordaram esse assunto, Verspagen (1997a), para países europeus, e Los e Verspagen (2000), Scherer (2003) e Wolff (2012), para os EUA, também encontraram valores positivos e estatisticamente significativos para $P \& D$ próprio e $P \& D$ intersetorial, no qual todos verificaram que o P\&D incorporado em bens de consumo possuem coeficientes maiores do que o P\&D próprio. Wolff (2012) e Scherer (2003), que também estimaram matrizes de investimentos, no entanto, verificaram um valor do coeficiente de $\mathrm{P} \& \mathrm{D}$ incorporado nos bens de capital maior do que o P\&D incorporado nos bens de consumo intermediário. Isso pode indicar a maior intensidade tecnológica dos setores fornecedores de bens de capital dos EUA e sua maior capacidade de impactar a produtividade de outras indústrias em comparação ao Brasil.

\section{Considerações finais}

Este artigo teve como objetivo principal analisar o impacto dos fluxos tecnológicos intersetoriais sobre a produtividade setorial no Brasil. A hipótese teórica levantada é de que boa parte do crescimento da produtividade deve ser explicada pelos gastos de $\mathrm{P} \& \mathrm{D}$ incorporados nos bens de consumo intermediário e de capital adquiridos pelos setores. Como discutido na seção 2, alguns estudos empíricos mostraram uma relação inconsistente entre inovação de processo e produtividade. Esses resultados podem ser explicados pelo fato de a maioria das inovações de processos serem produtos novos ou melhorados fornecidos por setores fornecedores. Dessa maneira, este artigo analisou não apenas o efeito de gastos em $P \& D$ de um setor sobre o crescimento de sua produtividade, como também o efeito sobre a produtividade dos gastos em $\mathrm{P} \& \mathrm{D}$ incorporados nos produtos adquiridos de outros setores.

De maneira geral, a hipótese de que os fluxos tecnológicos impactam o crescimento da produtividade do trabalho se confirmou. Para as variáveis de P\&D intersetorial os coeficientes das estimações apresentaram sinais positivos e foram estatisticamente significativos. Os fluxos tecnológicos incorporados nos bens de consumo intermediário apresentaram valores um pouco superiores aos fluxos tecnológicos incorporados nos bens de capital. Isso pode ser explicado pela estrutura de interdependência tecnológica setorial da economia brasileira. Sabe-se, por exemplo, que alguns setores de transferência tecnológica de bens de consumo no Brasil, como a indústria química e de petróleo, investem proporcionalmente muito em $\mathrm{P} \& \mathrm{D}$ e possuem muitas ligações a jusante. Já as transferências de capital estão restritas a poucos setores da economia, principalmente ao setor de máquinas e equipamentos. Outro ponto importante é que os fluxos tecnológicos internacionais não 
são analisados neste estudo, devendo-se chamar atenção que parte importante dos bens de capital adquiridos pelas empresas brasileiras são importados.

Esses resultados trazem duas consequências importantes do ponto de vista de análises setoriais. A primeira é que os estudos sobre inovação e produtividade ou crescimento econômico devem incorporar os fluxos tecnológicos intersetoriais para uma melhor compreensão da dinâmica de mudança estrutural. Algumas análises sobre o crescimento da produtividade nos últimos anos no Brasil vem ressaltando o maior crescimento desta na agropecuária e nas indústrias baseadas em recursos naturais e queda na indústria de transformação. No entanto, os resultados deste artigo mostram que uma parte importante dos ganhos de produtividade das atividades econômicas são explicadas por inovações de outros setores. Neste caso, por mais que a indústria manufatureira no Brasil vem apresentando queda na sua taxa de produtividade, não significa que a mesma não contribua para o crescimento de outros setores, inclusive da agricultura. A segunda consequência se refere às características do processo de difusão de inovações, que indicam uma visão sistêmica entre setores geradores e usuários. Isso pode trazer contribuições para formulações de políticas públicas de inovação que visem essas relações, levando em consideração os efeitos para trás e para frente nas cadeias produtivas.

Por fim, cabe ressaltar que este estudo apresentou resultados semelhantes com os dados de outros países, confirmando a importância dos fluxos tecnológicos para o crescimento da produtividade setorial. Isso pode explicar os resultados inconsistentes da fraca relação entre inovação de processo e produtividade nos trabalhos em nível da empresa discutidos na seção 2. No entanto, trabalhos empíricos sobre fluxos tecnológicos também ao nível da empresa devem ser testados para confirmar com mais precisão esse resultado, o que requer uma base de dados mais complexa e não disponível pelo menos para empresas brasileiras. Outra limitação do estudo é quanto a falta de uma mensuração dos fluxos tecnológicos importados. A aplicação das ferramentas abordadas neste artigo em matrizes de insumo-produto internacionais abre uma possibilidade de aperfeiçoamento de fluxos tecnológicos internacionais em estudos futuros sobre o tema.

\section{Referências}

ARELLANO, M.; BOND, S. Some tests of specification for panel data: monte carlo evidence and an application to employment equations. Review of Economic Studies, v.58, n.2, p. 227-297, 1991.

ARELLANO, M.; BOVER, O. Another look at the instrumental variable estimation of errorcomponents models. Journal of Econometrics, v. 68, n. 1, p. 29-51, 1995.

CRÉPON, B.; DUGUET, E.; MAIRESSE, J. Research, innovation and productivity: an econometric analysis at the firm level. Economics of Innovation and New Technology, v. 7, n. 2, p. 115-158, 1998.

GEROSKI, P. Innovation and the Sectoral Sources of UK Productivity Growth. Economic Journal, v. 101, p. 1438-1451, 1991.

GOTO, A.; SUZUKI, K. R\&D capital, rate of return on R\&D investment and spillover of R\&D in Japanese manufacturing industries. The Review of Economics and Statistics, v. 71, n. 4, p. 555$564,1989$.

GRIJÓ, E. BÊRNI, D.A. Metodologia completa para a estimativa de matrizes de insumo-produto. Teoria e evidência econômica, v. 14, n. 26, p. 9-42, 2006.

GRILICHES, Z.; LICHTENBERG, F. Inter-industry technology flows and productivity growth. Review of Economics and Statistics, v. 66, p. 324-9, 1984. 
GRILICHES, Z. Issues in Assessing the Contribution of R\&D to Productivity Growth. Bell Journal of Economics, v. 10, n. 1, p. 92-116, 1979.

GUILHOTO, J. J. M.; SESSO FILHO, U. A. Estimação da matriz insumo-produto a partir de dados preliminares das Contas Nacionais. Economia Aplicada, v. 9, n. 2, p. 277-299, 2005.

GUSTAFSON, W. E. Reserch and Development, new products and productivity change. American Economic Review, v 52, p. 177-185, 1962.

HANEL, P. Interindustry flows of technology: an analysis of the Canadian patent matrix and inputoutput matrix for 1978-1989. Technovation, v. 14, n. 8, p. 529-548, 1994.

IBGE - INSTITUTO BRASILEIRO DE ESTATÍSTICA E GEOGRAFIA. Sistema de Contas Nacionais - Brasil Referência 2010: Nota Metodológica ${ }^{\circ} 1$ - Implantação da série do SCN 2010. Coordenação de Contas Nacionais. Rio de Janeiro: IBGE, 2015

IBGE - INSTITUTO BRASILEIRO DE ESTATÍSTICA E GEOGRAFIA. Matriz de InsumoProduto: Brasil: 2010. Coordenação de Contas Nacionais. Rio de Janeiro: IBGE, 2016a.

IBGE - INSTITUTO BRASILEIRO DE ESTATÍSTICA E GEOGRAFIA. Pesquisa de Inovação: 2014. Coordenação de Indústria. Rio de Janeiro: IBGE, 2016 b.

IBGE - INSTITUTO BRASILEIRO DE ESTATÍSTICA E GEOGRAFIA. Comissão Nacional de Classificação (Concla), 2017a. Disponível em: < https://cnae.ibge.gov.br/>. Acesso: 05 dez 2017.

LOS, B.; VERSPAGEN, B. R\&D spillovers and productivity: evidence form U.S. manufacturing microdata. Empirical Economics, v. 25, n. 1, p. 127-148, 2000.

LUNDVALL, B. A. Innovation as an interactive process: from user-producer interaction to the national system of innovation. In: DOSI, G., FREEMAN, C., NELSON, R., SILVERBERG, G e SOETE, L. Technical change and economic theory, Pinter, London, 1988.

MILLER, R. E.; BLAIR, P. D. Input-output analysis: foundations and extensions. 2 ed. New York: Cambridge University Press, 2009.

MARENGO, L.; STERLACCHINI, A. Intersectoral technology flows: methodological aspects and empirical applications. Metroeconomica, v. 41, n. 1, p. 19-39, 1990.

MARTINEZ, T. S. Método RAWS/RAW para estimação anual da Matriz de Insumo-Produto na referência 2000 das Contas Nacionais. Texto para Discussão, Instituto de Pesquisa Econômica Aplicada (IPEA). Brasília, Rio de Janeiro: IPEA, 2015.

MIGUEZ, T. de H. L. Evolução da Formação Bruta de Capital Fixo na Economia Brasileira 2000-2013: Uma Análise Multissetorial a partir das Matrizes de Absorção de Investimento (MAIS). 2016. 155 f. Tese de Doutorado - IE, Universidade Federal do Rio de Janeiro, Rio de Janeiro, 2016.

MOHNEN, P.; HALL, B. H. Innovation and productivity: an update. Eurasian Business Review, v. 3, n. 1, p. 47-65, 2013.

MOMIGLIANO, F.; SINISCALCO, D. The growth of service employment: a reappraisal. BNL Quarterly Review, n. 142, p. 269-306, 1982. 
MOMIGLIANO, F.; SINISCALCO, D. Technology and international specialization. BNL Quarterly Review, n. 150, p. 257-284, 1984.

OCDE - ORGANIZAÇÃO PARA COOPERAÇÃO E DESENVOLVIMENTO ECONÔMICO. Oslo manual: guidelines for collecting and interpreting innovation data. Paris: OCDE, 2005.

PASINETTI, L. L. The notion of vertical integration in economic analysis. Metroeconomica, vol. 25, p. 1-25, 1973.

PASSONI, P. A.; FREITAS, F. Estrutura produtiva e indicadores de encadeamento na economia brasileira entre 2010 e 2014: uma análise multissetorial baseada no modelo insumo-produto. In: $\mathbf{4 5}^{\mathbf{0}}$ Encontro Nacional de Economia. Natal: ANPEC, 2017.

PASSONI, P. A. Estrutura produtiva e indicadores de encadeamento na economia brasileira entre 2000 e 2014: uma análise multissetorial baseada no modelo insumo-produto. Tese Doutorado - Instituto de Economia, Universidade Federal do Rio de Janeiro, Rio de Janeiro, 2018. No prelo.

RAVENSCRAFT, D.; SCHERER, F. M. The lag structure of returns to research and development. Applied Economics, v. 14, n. 6, p. 603-620, 1982.

ROODMAN, D. How to do xtabons2: an introduction to "difference" and "system" GMM in Stata. The Stata Journal, v. 9, n. 1, p. 86-136, 2009.

SCHMOOKLER, J. Invention and economic growth. Harvard: Harvard University Press, 1966.

SCHERER, F. M. Inter-industry technology flows and productivity growth, Review of Economics and Statistics, v. 64, p. 627-634, 1982b.

SCHERER, F. M. Using Linked Patent and R\&D Data to Measure Inter-Industry Technology Flows. In: GRILICHES, Z. R\&D, Patents, and Productivity. Chicago: University of Chicago Press, 1984.

SCHERER, F. M. Technology Flows Matrix Estimation Revisited. Economic Systems Research, v. $15, \mathrm{n} 3,2003$.

STERLACCHINI, A. R\&D, innovations, and total factor productivity growth in British manufacturing. Applied Economics, v. 21, p. 1549-1562, 1989.

TEMURSHOEV, U.; MILLER, R. E.; BOUWMEESTER, M. C. A note on the GRAS method. Economic Systems Research, v. 25, n. 3, p. 361-367, 2013.

TERLECKYJ, N. Direct and indirect effects of industrial research and development on productivity growth of industries. In: KENDRICK, J. W.; VACCARA, B. N. New development in productivity measurement analysis. Chicago: Chicago Un. Press, 1980.

VAN MEIJL, H. Measuring intersectoral spillovers: French evidence. Economic Systems Research, v. 9, n. 1, p. 9-23, 1997.

VERSPAGEN, B. Estimating international technology spillovers using technology flow matrices. Review of World Economics, v. 133, n. 2, p. 226-248, 1997a. 
VERSPAGEN, B, Measuring intersectoral technology spillovers: estimates from European from the European ans US patent office databases. Economic System Research, v. 9, n. 1, p. 47-65, 1997 b.

WOLFF, E. N. Spillover, linkages, and technical change. Economic Systems Research, v. 9, n. 1, p. 9-23, 1997.

WOLFF, E. N. Spillover, linkages, and productivity growth in the US economy, 1958 to 2007. In: ANDERSSON, M.; JOHANSSON, B.; KARLSSON, C.; LÖÖF, H. Innovation \& growth: from R\&D strategies of innovation firms to economy-wide technological change. Oxford Press, 2012.

\section{Anexos}

Tabela A1 - Correspondência da classificação setorial das MIPs 2000-2014 estimadas (35 Setores) com os códigos da CNAE 1.0, CNAE 2.0, SCN ref. 2000 e SCN ref. 2010

\begin{tabular}{|c|c|c|c|c|c|}
\hline & Setores & CNAE 1.0 & CNAE 2.0 & SCN ref. 2000 & SCN ref. 2010 \\
\hline 1 & Agropecuária & $01+02$ & 01 a 03 & $101+102$ & $191+192+280$ \\
\hline 2 & Indústria Extrativa & 10 a 14 & 05 a 09 & 201 a 203 & $580+680+791+792$ \\
\hline 3 & Alimentos e Bebidas & 15 & $10+11$ & 301 & 1091 a $1093+1100$ \\
\hline 4 & Fumo & 16 & 12 & 302 & 1200 \\
\hline 5 & Têxtil & 17 & 13 & 303 & 1300 \\
\hline 6 & Vestuário & 18 & 14 & 304 & 1400 \\
\hline 7 & Calçados e Couro & 19 & 15 & 305 & 1500 \\
\hline 8 & Madeira & 20 & 16 & 306 & 1600 \\
\hline 9 & Celulose e Papel & 21 & 17 & 307 & 1700 \\
\hline 10 & Impressão e Gravação & 22 & 18 & 308 & 1800 \\
\hline 11 & $\begin{array}{l}\text { Refino de Petróleo } \\
\text { e Biocombustíveis }\end{array}$ & 23 & 19 & $309+310$ & $1991+1992$ \\
\hline 12 & Química & 24 (exceto 245) & 20 & 311 a 317 & 2091 a 2093 \\
\hline 13 & Farmacêutica & 245 & 21 & 313 & 2100 \\
\hline 14 & Borracha e Plástico & 25 & 22 & 318 & 2200 \\
\hline 15 & Minerais não-metálicos & 26 & 23 & $319+320$ & 2300 \\
\hline 16 & Aço & 271 a 273 & 241 a 243 & 321 & 2499 \\
\hline 17 & Metalurgia não-ferrosos & $274+275$ & $244+245$ & 322 & 2492 \\
\hline 18 & Produtos de Metal & 28 & 25 & 323 & 2500 \\
\hline 19 & $\begin{array}{l}\text { Máquinas e Equipamentos, } \\
\text { Eletrônicos e Diversos }\end{array}$ & $\begin{array}{c}29+30+32+ \\
33+36 \\
\end{array}$ & $\begin{array}{l}26+28+ \\
31 \text { a } 33\end{array}$ & $\begin{array}{c}324 \text { a } 326+328+ \\
329+334\end{array}$ & $\begin{array}{c}2600+2800+ \\
3180+3300\end{array}$ \\
\hline 20 & $\begin{array}{l}\text { Máquinas e equipamentos } \\
\text { Elétricos }\end{array}$ & 31 & 27 & 327 & 2700 \\
\hline 21 & Automóveis & $341+342$ & $291+292$ & $330+331$ & 2991 \\
\hline 22 & Autopeças & 343 a 345 & 293 a 295 & 332 & 2992 \\
\hline 23 & Outros Transportes & 35 & 30 & 333 & 3000 \\
\hline 24 & SIUP & $40+41$ & 35 a 39 & 401 & $3500+3680$ \\
\hline 25 & Construção Civil & 45 & 41 a 43 & 501 & 4180 \\
\hline 26 & Comércio & 50 a 52 & 45 a 47 & 601 & 4500 \\
\hline 27 & Transporte e Armazenagem & 60 a 64 & 49 a 53 & 701 & $\begin{array}{c}4900+5000+ \\
5100+5280 \\
\end{array}$ \\
\hline 28 & Alojamento e alimentação & 55 & $55+56$ & 1102 & $5500+5600$ \\
\hline 29 & Comunicação e Informação & $642+72+92$ & 58 a 63 & 801 & $\begin{array}{c}5800+5980+ \\
6100+6280\end{array}$ \\
\hline 30 & Intermediação Financeira & 65 a 67 & 64 a 66 & 901 & 6480 \\
\hline 31 & Serviços Imobiliários & $70+71$ & 68 & 1001 & 6800 \\
\hline 32 & $\begin{array}{l}\text { Serviços prestados às } \\
\text { Empresas e Famílias }\end{array}$ & $\begin{array}{c}502+527+704+ \\
725+73+74+ \\
91 \text { a } 93+95 \\
\end{array}$ & $\begin{array}{c}69 \text { a } 82+ \\
90 \text { a } 97\end{array}$ & $\begin{array}{c}1101+1103+ \\
1106\end{array}$ & $\begin{array}{c}6980+7180+7380+ \\
7700+7880+8000+ \\
9080+9480+9700\end{array}$ \\
\hline 33 & Educação Privada & 80 & 85 & 1104 & 8592 \\
\hline 34 & Saúde Privada & 85 & 86 a 88 & 1105 & 8692 \\
\hline 35 & Serviços Públicos & $75+80+85$ & 84 a 87 & 1201 a 1203 & $8400+8591+8691$ \\
\hline
\end{tabular}

Fonte: Elaboração própria, a partir de classificações do IBGE (2016a; 2017). 
Tabela A2 - Estatísticas descritivas das variáveis de interesse da amostra

\begin{tabular}{lccccc}
\hline & Observações & Média & Desvio Padrão & Mínimo & Máximo \\
\hline$\Delta$ Produt & 175 & $-0,004$ & 0,0727 & $-0,1989$ & 0,2189 \\
Produt & 175 & $-2,730$ & 1,2154 & $-5,2231$ & 0,2434 \\
$\Delta$ Invest & 175 & 0,099 & 0,4429 & $-1,8330$ & 2,7461 \\
P\&D Próprio & 117 & $-5,674$ & 0,9655 & $-7,8990$ & $-3,4308$ \\
P\&D Absorvido A & 175 & $-6,941$ & 0,9257 & $-10,6944$ & $-4,9914$ \\
P\&D Inter A & 175 & $-7,267$ & 0,8103 & $-10,6944$ & $-5,9334$ \\
P\&D Absorvido L & 175 & $-5,659$ & 1,1849 & $-9,7074$ & $-3,1869$ \\
P\&D Inter L & 175 & $-6,453$ & 0,7102 & $-9,7074$ & $-5,3189$ \\
P\&D Absorvido B & 175 & $-9,039$ & 1,0870 & $-14,3986$ & $-5,9047$ \\
P\&D Inter B & 175 & $-9,066$ & 1,0966 & $-14,3986$ & $-5,9047$ \\
\hline
\end{tabular}

Nota: todas as variáveis estão em logaritmo.

Fonte: elaboração própria.

Tabela A3 - Correlação entre as variáveis de interesse da amostra

\begin{tabular}{|c|c|c|c|c|c|c|c|c|c|c|c|}
\hline & & 1 & 2 & 3 & 4 & 5 & 6 & 7 & 8 & 9 & 10 \\
\hline 1 & $\Delta$ Produt & 1,000 & & & & & & & & & \\
\hline 2 & Produt $t_{0}$ & 0,077 & 1,000 & & & & & & & & \\
\hline 3 & $\Delta$ Investimento & 0,264 & $-0,038$ & 1,000 & & & & & & & \\
\hline 4 & P\&D Próprio & 0,181 & 0,439 & $-0,100$ & 1,000 & & & & & & \\
\hline 5 & P\&D Absorvido A & 0,104 & 0,342 & $-0,120$ & 0,722 & 1,000 & & & & & \\
\hline 6 & P\&D Inter A & 0,048 & $-0,176$ & $-0,153$ & 0,090 & 0,472 & 1,000 & & & & \\
\hline 7 & P\&D Absorvido L & 0,177 & 0,455 & $-0,125$ & 0,973 & 0,831 & 0,194 & 1,000 & & & \\
\hline 8 & $\mathrm{P} \& \mathrm{D}$ Inter L & 0,010 & $-0,096$ & $-0,194$ & 0,029 & 0,417 & 0,897 & 0,151 & 1,000 & & \\
\hline 9 & P\&D Absorvido B & 0,026 & 0,050 & $-0,288$ & 0,013 & 0,231 & 0,368 & 0,093 & 0,469 & 1,000 & \\
\hline 10 & P\&D Inter B & 0,027 & 0,048 & $-0,280$ & $-0,017$ & 0,210 & 0,370 & 0,065 & 0,491 & 0,985 & 1,000 \\
\hline
\end{tabular}

Nota: todas as variáveis estão em logaritmo.

Fonte: elaboração própria. 